\section{Aventuras e desventuras de um biopirata}

\author{
Por José Augusto Drummond \\ Doutor em Land Resources pela Universidade de Wisconsin. \\ Professor Associado do Centro de Desenvolvimento \\ Sustentável da Universidade de Brasília \\ (jaldrummond@uol.com.br)
}

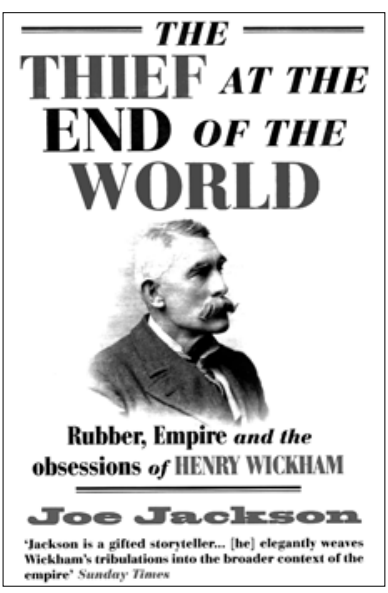

brasileira (ou melhor, de uma certa Amazônia brasileira, a do boom da borracha). Wickham foi o responsável por um dos atos mais famosos e consequentes do que hoje chamamos de 'biopirataria' - o furto de sementes da seringueira (Hevea brasiliensis) de seu habitat amazônico. Em 1875, aos 29 anos de idade, Wickham embarcou em Santarém, Pará, com destino à Inglaterra, carregando semi-clandestinamente 70.000 sementes de seringueira, colhidas na baixo rio Tapajós.

Quarenta anos depois, esse furto premeditado poria fim ao boom econômico e financeiro da borracha nativa extraída na região amazônica. Nas quatro décadas que se seguiram ao furto, cientistas, administradores coloniais e fazendeiros ingleses aprenderam a plantar a árvore e formaram vastas, ordeiras e homogêneas plantations (na Índia, Sri Lanka e Malásia, primeiramente) e a extrair o látex em escala industrial. A enorme produção e a alta qualidade desse látex 'domesticado' fizeram com que, a partir de 1914, ele dominasse o mercado internacional. Os seringais nativos da Amazônia viraram relíquias falidas, quase instantaneamente. Em 1905, a região produzia 99,7\% da borracha comercializada no mundo; em 1914, a cifra caíra para 39\%, chegando a apenas 6,9\% em 1922. O plantio 'racional' da seringueira liquidou a extração do látex nativo das seringueiras distribuídas 'irracionalmente' pela floresta amazônica. Foi o fim de uma era para a região.

Kew Gardens, o jardim botânico real da Inglaterra, situado em Londres, contratou formalmente Wickham para fazer esse furto, com a intermediação do cônsul inglês em Belém. Depois de vacilações e atrasos, Wickham foi feliz na seleção das sementes (grande quantidade, boa qualidade e isentas de doenças) no interflúvio dos rios Tapajós e Madeira, nas matas de terra firme perto de Boim, pequena localidade na margem esquerda do baixo rio Tapajós. Teve sucesso também ao burlar a vigilância da aduana brasileira no porto de Belém (embora a regulamentação brasileira sobre a retirada de materiais vegetais nativos do país fosse frouxa). A sua boa sorte continuou com a baixa mortalidade das sementes durante a longa viagem marítima até a Europa.

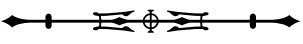


Wickham protagonizou, portanto, um eficaz ato de biopirataria, cujas consequências só se materializaram 40 anos depois. Um dos poucos outros relatos bem documentados sobre esse episódio é o de Warren Dean (1987), pesquisado e publicado há mais de 20 anos. Em termos gerais, Jackson corrobora Dean. No entanto, enquanto Dean focalizou o colapso geral do empreendimento da borracha amazônica em face do sucesso das plantações asiáticas da seringueira, Jackson, fiel ao gênero biográfico, se concentra no ato de furto das sementes e nas aventuras anteriores e posteriores de Wickham.

Um detalhe biográfico ressaltado pelo autor capta bem a gênese do espírito aventureiro de Wickham. Como adolescente, ele ficou impressionado com a forte repercussão de um episódio de biopirataria. Em 1859, o mesmo Kew Gardens promoveu, também na Amazônia, o furto de várias espécies do gênero Cinchona (ou Chinchona), arbustos de cujas cascas se retira quinino, usado até hoje no combate aos efeitos da malária. O autor desse outro ato famoso de biopirataria, Richard Spruce, renomado botânico inglês, conseguiu coletar exemplares de cinchona nas florestas tropicais de altitude do Equador e enviá-las para a Inglaterra. Mais tarde, elas foram cultivadas com sucesso em vários pontos do império britânico.

Jackson destaca que o bem sucedido furto de Wickham veio na esteira imediata de quatro anos de marasmo nos quais ele tentou se estabelecer como seringalista e fazendeiro nas imediações de Santarém, sem sucesso. Ainda antes disso, ele fizera excursões aventureiras quase fatais (bem descritas pelo autor) na Nicarágua e na Venezuela, das quais saiu falido, ferido e acometido de malária. Um dos pontos mais interessantes da narrativa de Jackson é que ele mostra que o furto das sementes não mudou a sorte pessoal de Wickham, embora o furto tenha tido repercussões econômicas enormes.

É verdade que Kew Gardens pagou a Wickham a quantia combinada (que não foi uma fortuna), mas ficou apenas nisso. Diretores e cientistas de Kew bloquearam as duas maiores ambições do biopirata. Ele desejava, primeiro, participar dos estudos de domesticação da seringueira e da eventual distribuição de mudas e sementes a jardins botânicos e fazendeiros ingleses nas colônias tropicais da Inglaterra na Ásia. Segundo, ele queria se tornar um dono de seringais plantados e um produtor de látex, ou seja, um dono de plantation, em alguma dessas colônias. Jackson mostra que os aristocráticos cientistas de Kew não confiavam em Wickham, duvidavam dos seus conhecimentos sobre a planta e desprezavam a sua origem plebeia e a sua pouca instrução formal. Wickham foi excluído das fases de domesticação da árvore e da expansão dos plantios.

Nem a sua 'boa fama' de biopirata ficou incólume. Jackson documenta como a própria equipe de Kew ajudou a espalhar a história (aparentemente equivocada) de que as mudas e sementes transferidas para Ásia descendiam de um outro lote de sementes, igualmente furtado e transferido do Brasil, por outro biopirata inglês, Robert Cross, também a serviço de Kew. Cross era um respeitado veterano das expedições que transferiram para o mesmo Kew Gardens exemplares da cinchona sul-americana, arbusto de alto valor por causa de suas propriedades medicinais. Ele coletou as sementes de seringueiras em torno de Belém, poucos meses depois de Wickham entregar as suas sementes em Londres.

Ressentido, mas não desanimado, Wickham logo partiu para outras aventuras, em outras terras, nas quais tentou se estabelecer como fazendeiro. Jackson narra coloridamente as suas passagens por Austrália, Honduras Britânica e Papua Nova Guiné. Faltou documentação para que Jackson montasse uma narrativa mais completa delas, mas o autor deixa claro o padrão de sucessivas aventuras e fracassos de Wickham.

Depois de sua estadia de quase cinco anos no Brasil, Wickham passou cerca de dez anos (1876-1886) em Queensland, na Austrália. Plantou café e fumo em terras compradas com o dinheiro ganho com as sementes de seringueira, mas foi à falência. A partir de 1886, tentou a

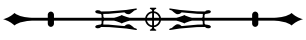


sorte na Honduras Britânica. De novo, não teve sucesso como fazendeiro, tendo perdido as suas terras por causa de dívidas e documentação fundiária inadequada, embora tenha ocupado cargos de escalão intermediário no governo colonial inglês. Em 1895, Wickham estabeleceu-se num remotíssimo arquipélago de 23 ilhas de coral (Contract Islands), na extremidade leste da Papua Nova Guiné. Por cerca de cinco anos produziu coco e mamão (de plantações), cultivou ostras, coletou esponjas marinhas e lesmas do mar e caçou tartarugas marinhas. Vítima de intermediários comerciais - iguais aos que na Amazônia o impediram de se tornar um seringalista -, mais uma vez o sucesso lhe escapou. Acabou endividado e foi praticamente expulso das ilhas. Desta vez, foi abandonado pela esposa Violet, uma valente inglesa, que o acompanhara ao Brasil, à Austrália, à Honduras Britânica e a essas ilhas.

Wickham retornou à Inglaterra pouco depois de 1900, mas ainda fez viagens ocasionais às possessões coloniais britânicas no Extremo Oriente. Continuava com o projeto de ser um grande fazendeiro. Investiu em uma plantação de seringueiras na Nova Guiné e em outra de piquiá (Caryocar villosum (Aubl.) Pers.), na Malásia, planta que ele conhecera no Brasil. Elas não foram para a frente.

Quase aos 60 anos de idade, Wickham ainda era um cidadão inglês quase anônimo e cronicamente falido. No entanto, como destaca Jackson, em torno de 1905 abriuse uma nova era para ele. Começou a ser reconhecido como o "herói provedor" das sementes de seringueira e, indiretamente, como corresponsável pelo espalhamento dos seringais e pelas riquezas que elas geraram. A borracha agora estava criando grandes fortunas para aqueles que plantavam seringueiras e se tornara imprescindível para a industrialização dos países ricos. $\bigcirc$ nome de Wickham ganhou fama ao mesmo tempo em que crescia a importância da borracha como commodity global.

À falta de outros sucessos, Wickham navegou com prazer na fama tardia conferida pelo seu feito biopirata de 30 anos antes. Publicou uma espécie de manual de cultivo da seringueira, incluindo um relato cheio de bravatas sobre o furto de 1875. Foi contratado como consultor de plantadores de seringueiras em várias colônias inglesas. Comparecia a eventos científicos e comerciais sobre a borracha, como um misto de perito em borracha e de celebridade. Ganhou prêmios em dinheiro de associações de plantadores de seringueiras, em reconhecimento do seu pioneirismo. Em 1920, recebeu da coroa inglesa um título de Knight e uma pensão vitalícia, pelo seu papel na expansão do império britânico. Morreu na Inglaterra, em 1928, sozinho, sem familiares por perto e, como sempre, falido. Jackson o descreve de forma impiedosa nos seus últimos anos: "Agora ele era simplesmente um personagem, uma figura amarga, cômica, com uma cabeleira branca e um bigode de leão marinho, que investia contra as novidades modernas dos plantadores de borracha da Malásia cujos bolsos ele enchera" (p. 285).

O livro de Jackson tem o mérito de manter o interesse do leitor sobre essa trajetória de muitos baixos e apenas um alto. Consegue isso mesclando a narrativa biográfica com a explicação da expansão da produção da borracha, essencial para a montagem da moderna estrutura industrial global. $\bigcirc$ tom geral da narrativa é de que a borracha enriqueceu países, empresas e pessoas, mas o seu "herói provedor" não colheu benefícios por causa da sua falta de vocação para o sucesso.

Jackson pesquisou como se fosse historiador profissional. Como cidadão relativamente obscuro, Wickham não ocupava manchetes jornalísticas, nem deixou arquivos pessoais, nem foi objeto de extensos relatos biográficos, contemporâneos ou recentes. Apenas um texto biográfico de peso foi publicado (na década de 1950) sobre ele antes do de Jackson. Apesar disso, o volume e a variedade das fontes usadas por Jackson impressionam. Elas incluem cartas familiares, grande número de documentos inéditos guardados em arquivos (Kew Gardens, governos da Inglaterra e de suas colônias, empresas ligadas à borracha), livros de viajantes e imigrantes contemporâneos, literatura científica (livros, artigos, teses), noticiário jornalístico, materiais impressos de origem empresarial e sites da internet. Jackson descobriu

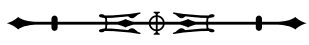


dados individuais de Wickham, familiares e associados nos recenseamentos nacionais ingleses. Entrevistou ou usou materiais genealógicos e autobiográficos de descendentes da família e de contraparentes de Wickham. O uso dos diários e das cartas de Wickham e da sua esposa foi especialmente importante para interpretar o trajeto do errático biopirata. A sua singular combinação de longo anonimato, persistência, fracasso e volatilidade só poderia ser bem captada por documentos de natureza mais íntima ou familiar.

Falta ao livro de Jackson um quadro ou um anexo contendo uma 'linha do tempo', uma cronologia que indicasse onde estava Wickham e o que ele fazia a cada ano, pois a sua trajetória irrequieta acaba confundindo o leitor. Há alguns erros de grafia de palavras em português ("aldeira" ao invés de aldeia; "guarapo" ao invés de garapa; "ciringal" ao invés de seringal) e algumas imprecisões nas datas. No entanto, a boa prosa e o sólido conteúdo não são invalidados por esses problemas localizados.

Quem gostará de ler esse livro? O texto é acessível a não-especialistas e fácil de ler. Ele pode interessar a vários tipos de leitores: estudiosos da Amazônia, da biopirataria, da história econômica mundial e da botânica; estudiosos das origens das plantas domesticadas; apreciadores de livros de viagem / aventura e de biografias; e estudiosos das economias extrativistas.

\section{REFERÊNCIA}

DEAN, Warren. Brazil and the Struggle for Rubber. Cambridge: Cambridge University Press, 1987. (Traduzido para o português como "O Brasil e a luta pela borracha". São Paulo: Ed. Nobel, 1991). 